\title{
Innovar o fracasar: claves para pensar una nueva institucionalización de los aprendizajes en la escuela del siglo XXI
}

\author{
Innovate or fail: keys to think about a new institutionalization of learning in the \\ 21st century school
}

Inovar ou fracassar: chaves para pensar uma nova institucionalização dos
aprendizados na escola do Século XXI

\author{
Cristina Rafaela Ricci \\ Centro de Investigación en Psicopedagogía \\ e Investigaciones Psicopedagógicas (CIPsp) \\ Buenos Aires, Argentina \\ crcristinaricci@yahoo.com.ar \\ (D) https://orcid.org/0000-0001-8092-5027
}

Recibido - Received - Recebido: 06 / 03 / 2021 Corregido - Revised - Revisado: 19 / 05 / 2021 Aceptado - Accepted - Aprovado: 24 / 05 / 2021

\author{
DOI: https://doi.org/10.22458/ie.v23i34.3451 \\ URL: https://revistas.uned.ac.cr/index.php/innovaciones/article/view/3451
}

\begin{abstract}
Resumen: Este ensayo partió de las preguntas: ¿qué hacer para que lo que ocurra en las aulas tenga algún sentido? y ¿qué hacer hoy con la escuela moderna? Estas preguntas cobran valor y urgencia, no solo en el contexto de pandemia por el virus responsable de la COVID-19, la cual ha dejado al descubierto fragilidades y potencialidades de las sociedades, estados, sistemas escolares y educativos; sino también en las primeras décadas del siglo XXI, frente al agotamiento de la escolarización masiva propia de la Modernidad en los siglos XIX y XX.

En el confinamiento y el aislamiento preventivo, obligatorio o sugerido en esta pandemia se ha vivenciado y evidenciado detrás de las pantallas el estallido -como suele ocurrir en no pocas aulas- de quejas y reclamos de la niñez, la juventud y las personas adultas, sintetizados en la pregunta: '¿para qué me sirve esto?', en relación con las prácticas de enseñanza y los contenidos escolares. El objetivo general de este ensayo es aportar elementos conceptuales que permitan pensar otros formatos escolares y el diseño de aulas y clases en los cuales los aprendizajes y la enseñanza cobren nuevo sentido para el estudiantado y la construcción de otro sujeto pedagógico.

Desde la perspectiva histórica, la psicología social, la pedagógica, la didáctica y la psicopedagógica, el análisis presentado permite concluir que no se trata de 'romper' con la escuela actual, sino que desde lo existente resulta necesario y posible instituir un movimiento sinérgico cambio-innovación toda vez que se conserve lo valioso de la enseñanza y se institucionalice otra concepción de aprendizaje.
\end{abstract}

Palabras clave: innovación educacional, escolaridad obligatoria, aula, aprendizaje, enseñanza, curriculum, evaluación de la educación.

Summary: This essay is based on the following questions: what to do, so that what happens in the classrooms makes any sense? And, what to do today with the modern school? These questions take on value and urgency, not only in the context of the pandemic caused by the virus responsible for COVID-19, which has exposed the weaknesses and potential of societies, states, school and education systems but in addition, in the first decades of the XXI century, in the face of the exhaustion of the massive schooling typical of Modernism in the XIX and $X X$ centuries

In the confinement and preventive isolation, mandatory or suggested in this pandemic, the outbreak has been experienced and evidenced behind the screens -as it usually happens in many classrooms- of complaints and claims from children, youth and adults, synthesized in the question: 'what is this for?', with regard to teaching practices and school content. The general objective of this essay is to provide conceptual elements that allow us to think about other school formats and the design of classrooms and classes in which learning and teaching take on new meaning for the student body and the construction of another pedagogical subject. 
From the historical perspective, regarding social psychology, and pedagogical, didactic and psycho-pedagogical psychology, the analysis presented allows to conclude that it is not a question of 'breaking' with the current school. However, based on what exists, it is necessary and possible to institute a synergistic movement of changeinnovation whenever the value of teaching is preserved and another conception of learning is institutionalized.

Keywords: Educational innovation, Mandatory schooling, Classroom, Learning, Teaching, Curriculum, Evaluation of education

Resumo: Este ensaio surgiu das perguntas: o que fazer para que o que acontece nas aulas faça sentido? E, o que fazer hoje com a escola moderna? Estas perguntas adquirem valor e urgência, não só no contexto da pandemia pelo vírus responsável pelo COVID-19, situação que evidencia não só as fraquezas bem como as potencialidades das sociedades, estados, sistemas escolares e educacionais, senão que também as nas primeiras décadas do século XXI perante o depauperamento da educação massiva dos séculos XIX e XX.

Diante do confinamento e isolamento de caráter preventivo, obrigatório ou recomendado durante esta pandemia tem-se vivenciado e demonstrado que detrás das telas - como acontece em muitas das aulas- se deu uma explosão de queixas e reclamos por parte das crianças, jovens e adultos sintetizada na pergunta: tudo isto serve para quê? Pergunta que faz referência às práticas de ensino e aos conteúdos escolares. O objetivo geral deste ensaio é contribuir com elementos conceituais que permitam pensar outros tipos de formatos escolares e de planejamento das aulas e lições nas quais os aprendizados e o ensino ganhem um novo sentido para os estudantes na construção de outro sujeito pedagógico. Desde uma perspectiva histórica, psicossocial, pedagógica, didática e psicopedagógica, a análise apresentada permite concluir que não se trata apenas de "romper" com a escola atual, senão que a partir do que existe é necessário e possível instituir um movimento sinérgico de mudança-inovação desde que o valor do ensino seja preservado e outra concepção de aprendizagem seja institucionalizada.

Palavras chave: Inovação educacional; escolaridade obrigatória; lição; aprendizagem; ensino; currículo; avaliação da educação

\section{INTRODUCCIÓN}

El contexto de pandemia por el virus responsable de la COVID-19 de 2020 (OMS, 2020), ha dejado al descubierto fragilidades y potencialidades de las sociedades y los estados en general, así como de los sistemas escolares y sistemas educativos, en particular. Estas fragilidades y potencialidades de los sistemas educativos son también el resultado del agotamiento de la escolarización obligatoria y masiva, emblema de la modernidad en los siglos XIX y XX.

Una de estas fragilidades manifestadas es la precariedad en la garantía de comunidad de la escolarización obligatoria. El hecho de pasar de forma abrupta y sin posibilidades de planificación de la presencialidad física a la presencialidad virtual, mediada esta última por tecnologías, no solo no ha sido garantía de continuidad de la escolarización obligatoria, sino que ha dejado al descubierto algo que ya acontecía en muchas aulas: las clases han perdido su sentido para gran parte del estudiantado y del profesorado.

Al mismo tiempo, lo anterior deja ver que el proceso de enseñanza y los procesos de aprendizajes se han transformado en asignación, resolución, entrega y corrección de tareas y actividades; es decir, en un intercambio cuasi mercantil.

La virtualidad opera en tanto terceridad, dado que rompe con la estructura dialógica del aula presencial, ubicándose en un recorrido visible para muchos. De esa manera, ya no es lo que dice el estudiante o lo que plantea el docente, es ciertamente lo que está descrito en ese no lugar, al que también asisten otros actores institucionales. En ese sentido, la terceridad democratiza. (Carlini López, 2020, p. 34).

También cabe señalar que el traslado del aula a los hogares ha permitido que muchos padres o adultos responsables del estudiantado se involucren de otro modo en el proceso educativo y escolar. Esto revela nuevas potencialidades en la construcción del vínculo escuela-familia y el vínculo al interior de 
las mismas familias. Sin embargo, la presencialidad mediada por tecnologías deja al descubierto otra fragilidad: las profundas diferencias socio-educativas e inequidad en la calidad de la escolaridad que padecen muchas familias.

En ese sentido, Salinas Ibáñez (2020) considera que si bien las tecnologías digitales en pandemia por el virus responsable de la COVID-19 han tomado relevancia en los procesos de enseñanza en el ámbito virtual, al mismo tiempo han quedado de manifiesto deficiencias crónicas del sistema educativo y el aumento de la desigualdad en el acceso al campo digital. Desde esta connotación el autor se pregunta:

¿Qué tipo de respuesta damos a los problemas sobrevenidos? ¿Seguimos poniendo parches o aprovechamos la oportunidad para una verdadera transformación del sistema educativo? Estamos hablando de una oportunidad más para el rediseño radical de la enseñanza y la reinvención de la carrera docente que incorpore el desarrollo de la competencia digital. (p. 17)

Ahora bien, en el confinamiento y el aislamiento preventivo, obligatorio o sugerido por los estados en esta pandemia, se ha evidenciado detrás de las pantallas el estallido -como suele ocurrir en no pocas aulas presenciales- de quejas y reclamos por parte del estudiantado, sintetizados en la pregunta: '¿Para qué me sirve esto?'. Pregunta por el sentido de muchas de las prácticas de enseñanza, los ritos y las rutinas naturalizados en las aulas y en relación con los contenidos escolares. Pregunta que muchas veces, demasiadas veces, recibe respuestas 'sin sentido' por parte del profesorado, educadores, adultos: 'Para la vida', 'No se sabe cuándo se necesitará', 'Para seguir estudiando y tener un futuro....".

Estas quejas y reclamos parecen indicar también el agotamiento de la lógica de la escolarización masiva moderna propia del estado-nación; es decir, el agotamiento de la escuela de la modernidad como dispositivo socio-político y del sujeto pedagógico configurado por ella. En definitiva, el contexto de pandemia por el virus responsable de la COVID-19, en orden a la escolarización y la educación plantea, nuevas preguntas, entre otras: ¿qué hacer para que lo que ocurra en las aulas tenga algún sentido? y ¿qué hacer hoy con la escuela moderna?

Una primera respuesta les corresponde darla a los gestores y administradores de las políticas públicas en materia de educación y a la sociedad en su conjunto. También corresponde que los especialistas en Ciencias de la Educación; es decir, a los especialistas en la enseñanza, los aprendizajes y educación formal, no formal e informal den respuestas.

Asimismo, corresponde al profesorado ofrecer respuestas. Una primera respuesta por parte de la persona docente es cambiando el modo de enseñar asociados a cambios paradigmáticos y no proponer cambios superficiales en las técnicas docentes, cuando no un mero incremento del uso de tecnología, como si el problema estuviera en utilizar las máquinas, como señala Bartolomé-Pina (2020).

Algunas respuestas desde la Pedagogía y la Didáctica las aporta Díaz (2020) cuando afirma: "las Pedagogías mediáticas y las perspectivas contemporáneas de la Didáctica se sostiene que en las construcciones metodológicas se revelan innovaciones didácticas que habilitan procesos de mediación y apropiación tecnológica en escenarios contemporáneos desiguales y atravesados por ecosistemas tecnológicos" (p. 50).

En esta misma línea de pensamiento, este ensayo científico presenta algunas perspectivas para comprender la construcción de sentidos sobre la educación y las situaciones de enseñanza en el actual escenario de incertidumbre educativa. Del mismo modo, este ensayo aporta claves desde las Ciencias de la Educación para transformar algunas prácticas de enseñanza, vinculadas con el diseño y la gestión de las aulas en entornos físicos y virtuales. 
Desde ese posicionamiento, el objetivo general de este ensayo es aportar elementos conceptuales que permitan pensar otros formatos escolares, desde los cuales los aprendizajes y la enseñanza cobren nuevo sentido para el estudiantado y el profesorado. Esto ayudará en la construcción de otro sujeto pedagógico; es decir, de otro tipo de relación e interacciones entre educador-educando, entre el profesorado y el estudiantado, entre las sociedades y los sistemas escolares.

Cabe considerar que se desprende una pregunta específica de las dos centrales de este artículo y es: ¿cómo de-construir representaciones sociales ancladas en la homogenización de la enseñanza obligatoria y construir nuevas representaciones sociales de los sujetos inmersos en los sistemas educativos?, la reflexión de Sangrà Morer (2020) acerca un principio de respuesta cuando afirma que es

[...] necesario diseño de modelos educativos híbridos que permitan transitar con fluidez entre momentos presenciales y momentos no presenciales, especialmente si estos no están programados. Además, es necesaria una visión integral de la escuela, que incluya tanto los contextos analógicos como los digitales, un liderazgo adecuado a la era digital que vivimos, y una formación inicial de los docentes. (p. 22)

A partir de la coincidencia con los puntos de vista, descripciones y respuestas con los autores mencionados, se desarrollarán algunas claves para responder a las preguntas: ¿qué hacer para que lo que ocurra en las aulas tenga algún sentido?, y, ¿qué hacer hoy con la escuela moderna? Para tal fin se consideran cinco perspectivas de análisis: la histórica, la psicología social, la pedagógica, la didáctica y la psicopedagógica.

\section{DESARROLLO}

Las perspectivas que a continuación se presentan son constitutivas del fenómeno de la escolaridad presencial y obligatoria de la modernidad. Estas permiten comprender al fenómeno de la escolaridad en sus orígenes y persistencia en el tiempo, al igual que permite plantear algunas claves para abordarlo y transformarlo. Estas perspectivas están imbricadas y aportan miradas simultáneas y complementarias, si bien por razones analíticas se presentan en forma sucesiva.

\section{Perspectiva histórica}

La historia de la educación permite comprender a la escuela, al aula y la clase escolar como construcciones históricas, socio-políticas y culturales, no sustanciales, dadas de una vez y para siempre. Más aún, la escuela moderna no fue una opción inevitable en la historia occidental, su historia es la historia de opciones políticas y culturales, de un proyecto formativo que no era para nada evidente ni necesario antes del siglo XIX.

La escuela moderna nació como una 'máquina de educar', como una tecnología replicable y masiva para aculturar grandes capas de la población, afirma Pineau (2005). La idea del acceso a la cultura o la educación para todos es propia de la modernidad, idea que se apoya en la concepción de un saber del hombre, de unas ciencias humanas que suponen una esencia humana cognoscible, como plantea Lewkowicz (2004).

A partir de estos supuestos, el Estado-nación junto con las sociedades modernas realizan un contrato por medio del cual se instituyen los sistemas escolares (educativos) como la organización jerárquica de la escuela como entidad socio-política. El fenómeno 'escuela' fue posibilitado por un profundo cambio 
pedagógico y social que acompañó el pasaje del siglo XIX al siglo XX. La expansión y consolidación de la escuela, como forma educativa hegemónica en todo el mundo occidental, se debe a que fue capaz de hacerse cargo de la definición moderna de educación: la escuela se transformó en símbolo y metáfora del progreso (Pineau, 2005).

La escolarización masiva como empresa moderna a cargo de la escuela, asumió una doble finalidad: formar al ciudadano e incorporarlo al mundo laboral. Esto lo realiza mediante la disciplina y la distribución homogénea de conocimientos y saberes bajo la forma didáctica de contenidos curriculares. Así, "la relación instrucción/disciplina (...) establece las fronteras precisas de lo educativo. El hombre educado es un hombre cultivado/disciplinado" (Pineau, 2005, p. 41).

Desde esta perspectiva, la escuela moderna impuso nuevas reglas de juego y reordenó el campo pedagógico ensamblando distintas piezas que la configuraron como organización cultural, social y política; tal configuración organizacional le permitió cumplir con su mandato-contrato fundacional: homogenizar formando ciudadanía y al trabajador.

Estas piezas son: a) homología entre la escolarización y otros procesos educativos, b) matriz eclesiástica, c) regulación artificial, d) uso específico del espacio y el tiempo, e) pertenencia a un sistema mayor, f) condición de fenómeno colectivo, g) constitución del campo pedagógico y su reducción a lo escolar, h) formación de un cuerpo de especialistas dotados de tecnologías específicas, i) el docente como ejemplo de conducta, j) una especial definición de la infancia, k) establecimiento de una relación inmodificablemente asimétrica entre docente y alumno, I) generación de dispositivos específicos de disciplinamiento, m) conformación de currículos y prácticas universales y uniformes, n) ordenamiento de los contenidos, ñ) descontextualización del contenido académico y creación del contenido escolar, o) creación de sistemas de acreditación, sanción y evaluación escolar, y p) generación de una oferta y demanda impresa específica: manuales, libros de lectura, cuadernos, láminas, leccionarios, entre otros (Pineau, 2005).

Estos elementos estructuraron lo que se dio en llamar 'la matriz escolar moderna'. Esta matriz condensa un conjunto de reglas, rituales y dispositivos que conformaron lo que se acuerda en llamar 'educación tradicional' desarrollada de manera masiva desde fines del siglo XIX y extendida en todo el mundo en el siglo XX, aún presente en los comienzos del siglo XXI.

La matriz escolar moderna queda así organizada sobre la base de cuatro grandes dimensiones: 1) el para qué del sistema, sus fines, el currículum en sentido amplio, el qué se busca que aprendan los alumnos; 2) la organización del sistema; 3) las pedagogías o prácticas de enseñanza dominantes; 4) los motores o fuerzas del aprendizaje de los alumnos (Rivas, 2017).

La matriz escolar tradicional tuvo su correlato en pedagogías conductistas que enseñaron de forma directiva, expositiva y repetitiva. Se trataba de un modelo "bancario": los docentes eran dueños del saber y los alumnos se sentaban a recibirlo, copiarlo y memorizarlo (Freire, 1975). La mayoría de lo aprendido, con el tiempo, se convertía en un "conocimiento inerte", que permite aprobar exámenes pero que nunca se vuelve a ver en la vida real (Perkins, 2010). La institucionalización del aprendizaje separó lo aprendido de sus posibles aplicaciones prácticas (Fernández Enguita, 2016) (Rivas, 2017, pp. 24-25).

Esto abona la hipótesis sostenida por Pineau (2005) relativa a que, la constitución de la escuela no es un fenómeno que resulta de la evolución 'lógica' y 'natural' de la educación, sino que la escuela puede considerarse el punto culiminante de la educación entendida como empresa moderna, en tanto proceso sobre el que se apoya su 'naturalización'. Sin dudas en el contexto actual, prosigue Pineau, tiene sentido continuar con algunas de estas viejas prácticas y conceptualizaciones, pero no porque las comprendamos como las únicas posibles, "sino porque las seguimos considerando las más eficaces para lograr los fines propuestos..." (Pineau, 2005, p. 50). 
Ahora bien, si la escuela no es un fenómeno natural y evolutivo sino histórico y contradictorio, las preguntas ¿qué hacer hoy con la escuela moderna?, ¿qué hacer para que lo que ocurra en las aulas tenga algún sentido?, adquieren relevancia, sobre todo si se pone en duda que es necesario seguir manteniendo viejas prácticas de enseñanza y las mismas conceptualizaciones que sustentaron la matriz escolar moderna por seguir considerándolas 'las más eficaces'.

Una prueba de que esas prácticas de enseñanza y de que algunas conceptualizaciones sobre educación y aprendizaje hoy tienen que ser revisadas, es el alto grado de fracaso, abandono escolar, abulia tanto del estudiantado como del profesorado. Por lo tanto, hoy frente a la escuela moderna, lo primero que se debería hacer es revisar cuáles elementos de ella son válidos y cuáles requieren ser modificados. Para ello, un procedimiento necesario es hacer que el estudiantado argumente su 'descontento', manifieste sus 'quejas', exprese sus 'reclamos', en definitiva, hagan audible qué sentido asignan al aprendizaje. Esto mismo, hacerlo extensible al profesorado para que visibilicen el 'sin sentido' de muchas de sus prácticas de enseñanza y pongan en valor la enseñanza como práctica social, política e histórica.

La resistencia y la subsistencia férrea de los formatos organizaciones de las escuelas, aulas y clases modernas junto con las viejas prácticas y conceptualizaciones, hoy están en tensión con las subjetividades post-modernas; por lo tanto, se requiere profundizar en las causas de dicha persistencia.

Algunas pistas explicativas se encuentran en la perspectiva psicosocial desde la cual, en articulación con esta perspectiva histórica, se puede afirmar que la persistencia de los dispositivos organizacionales y las prácticas pedagógicas, didácticas y psicopedagógicas de la escolaridad moderna se debe a su enraizamiento en ciertas Representaciones Sociales (RS) acerca de lo que 'es' la educación y acerca de lo que 'es' la escuela.

\section{Perspectiva de la psicología social}

La categoría RS aparece originalmente en la sociología clásica de Émile Durkheim y pasa por la psicología infantil con Jean Piaget, finalmente llega a la psicología social cognitiva con Serge Moscovici (1986).

Las RS constituyen modalidades de pensamiento social práctico orientadas hacia la comunicación, la comprensión y el dominio del entorno social sea material o ideal (simbólico). Se definen por su contenido (informaciones, imágenes, opiniones, actitudes, entre otros) que se relaciona con un fin, un trabajo a realizar. Pero también se definen como una relación entre sujetos: es la representación que se forma un sujeto de otro sujeto, representación que no es un duplicado de lo real o lo ideal: es la relación del ser humano con las cosas y los demás seres humanos.

Para el presente análisis comprensivo, la categoría RS es central porque la matriz escolar moderna hoy tan cuestionada por la sociedad, el estudiantado y el profesorado, conformó un determinado sujeto pedagógico; es decir, una determinada relación entre educador-educando en cuanto el primero es el depositario del saber y el segundo es el alumno (a: sin + lumen: luz = alumno es el 'sin luz').

Por lo tanto, las RS se refieren a la imagen mental que tiene una persona acerca de alguna cosa, persona, situación, evento, acción o proceso que percibe. Así, las RS pueden definirse como sistemas de valores, ideas y prácticas que tienen una doble función: establecer un orden que permita a los individuos orientarse en el mundo social, material y simbólico, y dominarlos. A la vez que, permitir la comunicación entre los miembros de una comunidad, aportándoles un código para el intercambio social y un código para dominar y clasificar de manera inequívoca los distintos aspectos de su mundo y su historia individual y grupal (Moscovici, 1986).

Las RS son construidas, por lo tanto, a partir de procesos de interacción y comunicación social, conversaciones de la vida diaria, recepción de los medios masivos, por citar algunos de esos procesos. Estos 
procesos comunicacionales. los cuales también reconstruyen los sujetos, se cristalizan en prácticas sociales en tanto construcciones simbólicas. Si en este punto, se retoma la pregunta: ¿qué hacer hoy con la escuela moderna? Una respuesta válida es: modificar ciertas prácticas sociales, como ser las prácticas de enseñanza porque en la naturaleza simbólica de las RS quedan plasmados los aspectos sociales, culturales e históricos. Estas modificaciones posibilitan la de-construcción o el agrietamiento de algunas RS vinculadas a la matriz escolar moderna, a la vez que habilitan la construcción de otras RS.

En este sentido, la representación es una construcción de la realidad que una vez construida, existe casi independientemente de ese aspecto de la realidad que es representado, como por ejemplo: la escuela.

En palabras de Jodelet (1986), las RS son imágenes que condensan un conjunto de significados y sistemas de referencia que permiten interpretar lo que sucede, e incluso dar un sentido a lo inesperado; de categorías que sirven para clasificar las circunstancias, los fenómenos y los individuos con quienes se tiene algo que ver, aportan una manera de interpretar y de pensar la realidad cotidiana, son en definitiva una forma de conocimiento social. Y, correlativamente, producen la actividad mental por la que individuos o grupos fijan su posición en virtud a situaciones, acontecimientos, objetos y comunicaciones que les conciernen. Por lo tanto, al interior de los sistemas escolares los distintos actores involucrados en los procesos de gestión y administración, de enseñanza y aprendizaje pueden construir nuevos sentidos a sus prácticas institucionales.

Por su parte, Abric (1994) sostiene que en una RS hay dos elementos de naturaleza disímil y dos componentes: un núcleo central y elementos periféricos y, el contenido y la organización de ese contenido que reposa sobre una jerarquía entre los elementos determinada por el núcleo central. El sistema central tiene dos funciones: generar el significado principal de la representación y determinar la organización de los otros elementos que no agotan el conjunto de la representación. El sistema periférico está compuesto por todos los otros elementos de la representación responsables de la movilidad, flexibilidad y diferencias entre los individuos. Por tanto, permite la integración de las experiencias e historias individuales y se apoya en la evolución, contradicciones y heterogeneidad del grupo. A diferencia del sistema central, este sistema es más sensible al contexto inmediato y permite la adaptación a prácticas sociales concretas así como diferenciar el contenido de la RS para proteger al sistema o núcleo central de una rápida transformación.

Lo anterior permite pensar en ciertos límites en la búsqueda de respuestas a las preguntas: ¿qué hacer para que lo que ocurra en las aulas tenga algún sentido?, y, ¿qué hacer hoy con la escuela moderna?

Ahora bien, en cuanto a la génesis de las RS esta puede ser descripta como una sociogénesis, una ontogénesis y una microgénesis (Duveen y Lloyd, 2003). En el primer caso, una comunidad produce representaciones de manera colectiva, mediante la interacción y estas pueden captarse únicamente por medio de una perspectiva diacrónica; pues se trata de un proceso histórico vinculado con la construcción y transformación de las RS de los grupos respecto de objetos o personas específicos.

En el caso de la escolarización moderna, las RS se fueron construyendo en el siglo XIX. La ontogénesis hace referencia a la construcción de RS a lo largo de la vida de una persona quien conforma una identidad social concreta, aunque esto no signifique que se trate de una creación individual. Por lo tanto. los procesos de ontogénesis están relacionados con el desarrollo de los individuos en relación con las RS. Esto queda plasmado en el sujeto pedagógico moderno mediante los mecanismos de formación del magisterio y el aprendizaje del 'oficio de alumno'.

Finalmente, la microgénesis es un concepto que pretende capturar el instante mismo en que los sujetos interactúan, debaten, charlan, resuelven conflictos y, de este modo, negocian identidades sociales y las representaciones en que se basan y establecen marcos de referencia compartidos. Por lo tanto, estos procesos están relacionados con la evocación de las RS en la interacción social, en este caso en el contexto escolar: tanto el enseñante como el aprendiente actúan según las RS cristalizadas en la matriz 
escolar moderna, incluso más allá, en el caso del profesorado, de la formación recibida más acorde con las nuevas teorías y perspectivas sobre el acto pedagógico.

De acuerdo con lo anterior descrito, la sociogénesis y la ontogénesis de las RS implican siempre procesos de microgénesis como condición de posibilidad para la persistencia de prácticas y formatos institucionales instituidos en otro momento histórico. Un ejemplo de ello es que, los países latinoamericanos han sufrido constantes cambios en las concepciones y las estrategias de sus sistemas educacionales; $\sin$ embargo, las sucesivas y las diferentes propuestas de reforma, impulsadas sobre todo a partir de 1960 y, sobre todo las reformas de la década de 1990, han tenido como características haber abarcado casi todos los aspectos susceptibles de ser transformados en los sistemas educacionales y los escasos resultados de dichos cambios.

Junto con esos fracasos generalizados se instaló cierto determinismo y escepticismo acerca de las posibilidades reales de modificar el funcionamiento de la administración de los sistemas educacionales y de las prácticas de enseñanza.

Otro ejemplo, es la incapacidad de los Planes de Mejora Institucional (PMI) generalizados en los sistemas escolares y educativo de la región para incidir y modificar la progresiva disociación de esos sistemas, tanto respecto del pensamiento pedagógico heredado de la modernidad como de la disociación de las exigencia sociales externas: el sistema educativo se estaría constituyendo en un área donde predomina cada vez más intensamente una lógica propia (inercia institucional), basada en la conservación de sus rasgos internos y no en la satisfacción de requerimientos externos, sean estos de tipo social, cultural o científico.

¿Cómo operan las RS para perpetuar el ethos de la escolaridad moderna? En principio operan a partir de la construcción epocal de un determinado sujeto pedagógico (relaciones e interacciones) y la microgénesis puesta en acto en esa relación.

La categoría conceptual 'sujeto pedagógico' busca significar una relación específica, la relación pedagógica, por sujeto se comprende tanto al educador como al educando. Constituye, pues, el resultado de una interacción entre sujetos sociales complejos, comprometidos en una situación educativa mediada por un currículo, manifiesto u oculto: “Por ello, cuando se habla de sujeto pedagógico, se está hablando también de currículo (...) [como] síntesis de los elementos culturales (conocimiento, valores, costumbres, régimen disciplinario, creencias) como a la táctica escolar" (Puiggrós, 1990, p. 237).

Por lo tanto, hay que considerar como plantea Puiggrós (1990) que la educación constituye un producto y una práctica social compleja que se desarrolla en un marco de condiciones de producción propias e internas y sus correspondientes relaciones con los factores externos, como lo son los procesos sociales (sociogenénesis de las RS). Estos procesos son mediatizados por medio del vínculo pedagógico, de tal forma se conforma un sujeto pedagógico en tanto sujeto político y social.

Este sujeto pedagógico deviene la cristalización de tendencias pedagógicas sobre-determinadas por los factores externos que no actúan directamente en el proceso educativo, sino por medio de una relación pedagógica (ontogénesis de las RS), así se consolida la matriz escolar moderna, en este caso, puesta en acto por el sujeto pedagógico en sus interacciones (microgénesis de las RS).

Al mismo tiempo, este sujeto pedagógico es el resultado de un modelo pedagógico dominante que, además de reproducir el mandato y la cultura del sector o sectores sociales dominantes, presenta una trama permeable a discursos desestructurantes, los cuales pueden llevar a la parcial negación de aqueIla cultura o mandato por medio del discurso alternativo, observa Puiggrós (1990). Por lo tanto, la deconstrucción de ciertas RS es difícil pero posible: así como en la modernidad se construyó un sujeto pedagógico basado en una relación en la que el educador era el portador de una cultura superior que 
debía imponer a un sujeto negado socialmente, el educando. En esta relación, el estado debía garantizar la formación especializada del profesorado y la educación de la población.

En el cambio de época, emprender la empresa de construcción de otro sujeto pedagógico sería una respuesta a las preguntas de ese ensayo. Para ello, no hay que perder de vista que la reivindicación de opciones pedagógicas no implica, necesariamente, desconocer la serie de significantes y sentidos presentes en la historia de la educación. Por el contrario, se trata de que la historia de la educación sirva de referente y, por lo tanto, de discurso explícito al que hay que recurrir para construir nuevos sentidos. Esto llama a revisar la concepción de educación la que se estructuraron los sistemas educativos modernos en occidente.

\section{Perspectiva pedagógica}

Una vez que se tiene presente en el horizonte comprensivo los procesos de configuración de RS y de construcción de un tipo específico de sujeto pedagógico propios de una episteme epocal, representada por las condiciones de posibilidad para que unos discursos accedan al estatus de verdaderos en detrimento de otros (Foucault, 1975), podremos avanzar en la comprensión del concepto de educación sobre la que se estructuraron los sistemas escolares modernos.

En términos educativos el siglo XX, se inició con el establecimiento del 'reinado' escolar y su notable expansión global, empresa que fue llevada a cabo sobre la definición de educación planteada desde la Sociología por Durkheim como

[...] la acción ejercida por las generaciones adultas sobre las que todavía no están maduras para la vida social. Tiene por objeto suscitar y desarrollar en el niño cierto número de estados físicos, intelectuales y morales, que exigen de él la sociedad política en su conjunto y el medio especial, al que está particularmente destinado (Durkheim [1911], 1984, p. 70).

Como señala Pineau (2005), Durkheim despega la educación de cualquier definición trascendental y la limita a la esfera de lo social: la moral es la moral social. Por lo tanto, "De fenómeno esencialmente humano en Kant, la educación se vuelve un fenómeno esencialmente social en Durkheim [quien] determina muy fuertemente el lugar del educador (las generaciones adultas) y del educando (quien no está todavía maduro para la vida social)" (Pineau, 2005, pp. 47-48).

La educación moderna se presenta como un proceso de 'completud' del sujeto, sujeto inacabado en lo individual y lo social. Este concpeto de educación moderna nos sitúa en un tipo de cultura, la cultura post-figurativa en la que los niños y los jóvenes aprenden primordialmente de los mayores. Este tipo de cultural está alejado de la cultura co-figurativa, en la cual tanto los niños y los jóvenes como los adultos aprenden de sus pares $y$, de la cultura pre-figurativa en la que los adultos también aprenden de los niños y los jóvenes, según las caracteriza Margaret Mead (1980).

En este contexto de cambio de época en el que coexisten estos tres tipos culturales una nueva definición de educación es necesaria. Otra definición de educación sobre la cual establecer otro contrato entre la sociedad, el estado y la escuela (los sistemas escolares), basado en la construcción de otro sujeto pedagógico y la de-construcción de algunas RS.

Una nueva concepción de educación tendría que considerar, entre otros elementos: la coexistencia de tres tipos culturales: post-figurativo, co-figurativo y pre- figurativo; un nuevo contrato que incluya tres actores, en lugar de dos: las sociedades, los estados y las culturas. Por lo tanto, pensar a la educación en y para la diversidad basada en la igualdad sustentada en la común condición humana y, en la diversidad 
como sujetos, pueblos, culturas. Una concepción de educación en la que la diversidad es vista y querida como valor, como una riqueza y no despreciada y soportada como un problema, como una dificultad: diversidad cultural y diversidad psicopedagógica, entre otras diversidades.

Una vez más se retoman las preguntas rectoras de este ensayo: ¿qué hacer para que lo que ocurra en las aulas tenga algún sentido?, y, ¿qué hacer hoy con la escuela moderna? Lo que se debe hacer es, desde la perspectiva pedagógica, consensuar una nueva concepción histórica de educación que debería incluir a las culturas como parte de los procesos pedagógicos, didácticos y psicopedagógicos; incluir el enfoque de la Educación como Derecho articulándolo sinérgicamente con el Derecho a la Educación.

Lo anterior implica reconocer que el sujeto es la fuente de los derechos: los derechos son intrínsecos a la condición humana. Implica considerar que las sociedades, los estados, las instituciones deben reconocer esos derechos, no asignarlos. Implica comprender que una tarea de la educación es brindar herramientas, experiencias, saberes, estrategias para desarrollar los derechos y ejercer el "derecho a tener derechos". Implica admitir que la educación puede ser entendida como "un derecho que da derechos".

En definitiva, lo que hay que hacer para que algo de lo que ocurra en la escuela tenga sentido, es construir otra relación pedagógica: Relación dialógica, relación asimétrica en los roles, funciones y responsabilidades; relación simétrica en la común condición y dignidad humana, en el mutuo reconocimiento, el mutuo cuidado, el mutuo respeto. En síntesis, como se viene sosteniendo: lo que hay que hacer otro sujeto pedagógico en otra escuela. Si la modernidad lo logró y fue eficaz, la post-modernidad tiene al menos que intentarlo para no seguir fracasando.

En la construcción de este nuevo pacto educativo y escolar, disciplinas como la Didáctica y la Psicopedagogía pueden aportar elementos innovadores, si por innovación entendemos esa fuerza vital, presente en escuelas, educadores, proyectos y políticas, la cual es capaz de reconocer las limitaciones de la matriz educativa tradicional y alterarla para el beneficio de los derechos de aprendizaje del siglo XXI de nuestros estudiantes. Si se expresa en otros términos, innovar es alterar los elementos de un orden escolar que apagan o limitan el deseo de aprender de los estudiantes, como la define Rivas (2017).

Sin embargo, no hay que olvidar que una concepción instrumental de la Didáctica fue funcional a la matriz escolar moderna cuando centró sus propuestas de enseñanza en el método único para enseñar a un alumno a-histórico, descontextualizado. Sin embargo, la Didáctica en las dos primeras décadas del siglo $\mathrm{XXI}$, al menos en algunos países, se redefinió como una disciplina situada cuyo objeto de conocimiento e intervención es los procesos de enseñanza y los procesos de aprendizajes contextualizados para dejar atrás la concepción y la práctica del método único y universal.

Por otra parte, es bueno recordar que la matriz escolar moderna generó nuevas patologías de época: el problema de aprendizaje, los trastornos en los aprendizajes, las dificultades de aprendizaje. Estas 'patologías' comienzan a instalarse a finales del siglo XIX y comienzos del siglo XX en los sistemas escolares $y$, a naturalizarse en las sociedades. Comienza a ser 'normal' que algunos sujetos no pueden adecuarse a la regulación artificial de los tiempos, espacios y modos para enseñar y para aprender propuestos por la escuela moderna.

Así, según lo anterior, se construye el binomio normal-anormal y el constructo 'alumnos' con 'problemas' de 'aprendizaje' o de 'conducta' porque no pueden adaptarse a las prácticas escolares universales y uniformes, un contenido escolar descontextualizado, asituaciones áulicas artificiales, sistemas de acreditación, evaluación, sanción y disciplinamiento escolar considerados como 'normales', 'normalizados', 'normalizadores'. Esto, instaló a muchos sujetos en el no-deseo por el conocimiento en el marco de instituciones escolares que se convirtieron en des-subjetivantes para muchos sujetos, para quienes, 'fracasar en la escuela' fue y es, sinónimo de 'fracasar en la vida'. 
Este fenómeno dio origen a una nueva disciplina, profesión y campo: la Psicopedagogía. Estas consideraciones nos llevan a profundizar en algunos elementos presentes en las perspectivas didáctica y psicopedagógica como claves para la deconstrucción-construcción de otros sujetos pedagógicos.

\section{Perspectiva didáctica}

Enseñar es la dimensión central y constitutiva del quehacer docente, la situación de enseñanza (la clase) es el objeto de conocimiento e intervención de la Didáctica.

Por lo tanto, enseñar implica la toma de decisiones en el desarrollo curricular, la planificación didáctica y el diseño y gestión de ambientes significativos, subjetivantes, relevantes, sugestivos, que convoquen la puesta en acto de procesos de aprendizajes. Esto es lo que el estudiantado está reclamando no solo en este contexto de pandemia por el virus responsable de la COVID-19.

Para que eso ocurra, la elaboración de materiales de enseñanza, el uso de medios y recursos, la creación de estrategias de enseñanza que superen la lógica aplicacionista, propia de la modernidad, es una de las respuestas a las dos preguntas rectoras de este ensayo. Otra aproximación a respuestas posibles es considerar que las prácticas de enseñanza asumen el carácter de prácticas sociales históricamente condicionadas, situadas; por lo tanto, resultan ser prácticas altamente complejas, que no pueden reducirse a la repetición de 'recetas metodológicas'.

Los procesos de enseñanza, en tanto prácticas sociales responden a necesidades y determinaciones que están más allá de las intenciones y previsiones individuales de sus agentes directos o personas facilitadoras: solo pueden comprenderse en el marco de los contextos sociales e institucionales del que forman parte (Chevallard, 1998; Camillioni, 2008; Stenhouse, 1999; Edelstein, 2013).

Desde esta visión, los desarrollos de Díaz Barriga (2005) resultan esclarecedores porque al considerar al conocimiento como conocimiento situado, es decir:

[...] producto del aprendizaje o de los actos de pensamiento o cognición [que] puede definirse como situado en el sentido de que ocurre en un contexto y situación determinada, y es resultado de la actividad de la persona que aprende en interacción con otras personas en el marco de las prácticas sociales que promueve una comunidad determinada (...) [Sin embargo,] en buena medida el fracaso de las instituciones educativas reside en que se intenta enseñar un conocimiento inerte, abstracto y descontextualizado de las situaciones en que se aprende y se emplea en la sociedad. Debido a lo anterior, lo que se enseña en las aulas alberga una escasa motivación para los alumnos, y se concibe como poco comprensible y apenas útil (...) en un modelo de enseñanza situada, resaltarán la importancia de la influencia de los agentes educativos, que se traducen en prácticas pedagógicas deliberadas, en mecanismos de mediación y ayuda (...) ajustada a las necesidades del alumno y del contexto, así como de las estrategias que fomenten un aprendizaje colaborativo o recíproco. Lo anterior implica que en la toma de decisiones pedagógicas y didácticas (delimitación de intenciones, selección y tratamiento de contenidos, previsión de estrategias docentes y para el aprendizaje, mecanismos de evaluación, entre otros) juega un papel protagónico la consideración de las situaciones reales en las que el sujeto ha recreado, recrea o deberá recrear el conocimiento que habrá de adquirirse en el escenario escolar (Díaz Barriga, 2005, pp. 20-21).

Por lo tanto, puede indicarse que lo propio y específico de la educación escolar es estar formada por un conjunto de actividades especialmente planificadas, con el fin de suscitar y ayudar al estudiantado a asimilar aquellas formas o saberes culturales que son consideradas por las sociedades como esenciales para su desarrollo y socialización, bajo la forma institucional de contenidos curriculares. 
Dichos contenidos difícilmente serían asimilados sin el concurso de una acción específica: la enseñanza (Coll, 1995). Por lo tanto, para que tenga algún sentido en las aulas y de-construir la matriz escolar moderna, es necesarioi visualizar al conocimiento como conocimiento situado y a las prácticas de enseñanza como prácticas sociales históricamente condicionas es otra respuesta posible.

Otras respuestas asumen el formato de claves didácticas que pueden colaborar en la construcción de un nuevo sujeto pedagógico. Estas son la selección, jerarquización y organización de los contendidos a enseñar y así establecer el alcance de estos, para cada situación de enseñanza y cada sujeto. Esto implica que el profesorado desarrolle la capacidad de establecer el grado de especificidad del contenido $y$, al mismo tiempo, considere la estructura cognitiva del estudiantado, establecer un cerco cognitivo específico (conocimiento situado), así delimita el objeto de enseñanza y aprendizaje, el sentido personal y la relevancia social y cultural de este. Esta delimitación posibilita que el sujeto del aprendizaje pueda construir significados y atribuir sentidos en el proceso de apropiación de contenidos como una puesta en acto del deseo (pulsión epistemofílica).

Otra clave didáctica para la construcción de otro sujeto pedagógico y de sentido es la evaluación o, más precisamente, el proceso de evaluación. En ese sentido, señala Litwin (2008) que las buenas prácticas de evaluación son "prácticas sin sorpresas; enmarcadas en la enseñanza y que se desprenden del clima, ritmo y tipo de actividad de la clase, por lo tanto son "prácticas atractivas para los estudiantes y con consecuencias positivas respecto de los aprendizajes" (Litwin, 2008, p. 173). Entonces se puede considerar que

[...] la evaluación es parte de la enseñanza y, por lo tanto, debe estar presente en la planificación. En el momento de planificar una secuencia de clases, un programa, una unidad, es necesario considerar también la evaluación. En efecto, hay que establecer en qué momentos se recogerá la información; definir qué aprendizajes debe lograr el estudiante y cómo se vinculan con los propósitos que el profesor se ha propuesto; seleccionar y elaborar instrumentos de evaluación, además de anticipar modos de realizar devoluciones a los estudiantes que contribuyan al logro de los aprendizajes (Anijovich y Cappelletti, 2017, pp. 21-22).

Estas claves didácticas implican promover el pasaje de aulas homogéneas propias de la escuela de la modernidad, a aulas heterogéneas, en las que cada sujeto ponga en juego sus propias matrices, estilos, modalidades, tiempos y ritmos de aprendizajes. En estas aulas heterogéneas los contenidos curriculares situados y los procesos de evaluación se centran y focalizan en los logros personales que varían para y en cada sujeto (Ahumada, 2005).

Pensar la clase (situación de enseñanza) en clave de heterogénea implica reconocer la existencia de diferencias entre las personas, en sus experiencias anteriores, sus estilos de aprendizaje, sus intereses, sus culturas, los distintos tipos de inteligencia, entre otras variables. También significa reconocer diferencias en las prácticas de enseñanza cotidianas en las escuelas, los estilos de gestión institucional, las actividades en otros escenarios didácticos, con otro diseño del espacio y el tiempo escolares. Asimismo, implica la revisión de los modos de interacción social entre los actores de la institución educativa y con otras instituciones (Anijovich, 2014).

Finalmente, el pasaje de la homogeneidad propia de la escuela moderna a la heterogeneidad escolar remite a buscar respuestas desde la perspectiva psicopedagógica, porque sitúa de lleno en la cuestión del sujeto de los aprendizajes. 


\section{Perspectiva psicopedagógica}

La Psicopedagogía surge a mediados del siglo XX como la profesión del 'problema de aprendizaje'. Esta profesión que interviene cuando un sujeto no puede establecer un vínculo con un objeto de conocimiento institucionalizado o tiene dificultades para hacerlo. A principios del siglo XXI, la Psicopedagogía como profesión amplía sus ámbitos de intervención y como disciplina científica reconfigura su objeto de conocimiento y el propio quehacer psicopedagógico.

Hoy, el objeto y el quehacer psicopedagógico están relacionados con los procesos situados de aprendizajes que los sujetos, en contexto construyen a lo largo de las edades de la vida. Al mismo tiempo que considera las vicisitudes que esos procesos de construcción de aprendizajes conllevan y las formas de subjetividad producidas en el acontecer de estos. Tales procesos se presentan cada vez más asociados a modalidades, estilos y matrices de aprendizajes heterogéneos y singulares (Ricci, 2020).

Por tanto, cada persona tiene un singular molde relacional que irá utilizando en las diferentes situaciones del aprendizaje (Fernández, 2000). Al mismo tiempo, el sujeto mantiene la tensión entre lo que se impone como repetición y permanencia de un modo anterior de relacionarse y, lo que necesita cambiar en ese mismo modo de relacionarse con el objeto a conocer, consigo mismo como autor de sus aprendizajes y con el otro como enseñante (Reaño, 2011). Esta modalidad de aprendizaje se va estructurando en la interacción del sujeto con el medio y, de esta manera, se va conformando una 'matriz de aprendizaje', es decir:

[...] un modelo interno de aprendizaje con el que cada sujeto organiza y significa el universo de su experiencia, su universo de conocimiento. Esta matriz es una estructura interna, compleja y contradictoria, y se sustenta en una infraestructura biológica. Está socialmente determinada e incluye no sólo los aspectos conceptuales sino también afectivos, emocionales y esquemas de acción. Este modelo, construido en nuestra trayectoria de aprendizajes, sintetiza y contiene cada aquí y ahora nuestras potencialidades y nuestros obstáculos. Estas matrices no constituyen una estructura cerrada, sino una gestalt, una estructura en movimiento, susceptible de modificación salvo casos de extrema patología (...) partir de estas matrices la persona va constituyendo su identidad en un proceso de relaciones en el que aprende a aprender. Esta matriz subyacente no consiste solo en una forma de relación sino que incluye un sistema de representaciones que interpreta ese encuentro. Aporta una hipótesis sobre quienes somos nosotros aprendiendo, es decir, qué lugar y qué tarea nos cabe en ese encuentro, qué es lo permitido en el acto del conocimiento, qué es lo posible, qué es trasgresión (Reaño, 2011, pp. 15-16).

Cada matriz de aprendizaje está multi-determinada y surge por la interacción de varios factores y relaciones sociales. Sin embargo, una matriz se encuentra rígida cuando pierde plasticidad y el sujeto muestra un detreimiento, una disminución o daño del desempeño habitual, ya sea en un área determinada de sus actividades, por ejemplo: el área intelectual, como así también en la totalidad de sus actividades (Reaño, 2011).

En estas relaciones de las personas entre sí y con los objetos de conocimiento se observa algo que se repite, que se mantiene constante y, algo que cambia, que se modifica a lo largo de la vida. Aquello que se modifica es la modalidad de aprendizaje.

Ese molde o esquema de operar que se va a ir utilizando en diferentes situaciones de aprendizaje. Es un molde, pero un molde relacional (...) La modalidad de aprendizaje marcará una forma particular de relacionarse, buscar y construir conocimientos, un posicionamiento del sujeto ante sí mismo 
como autor de su pensamiento, un modo de descubrir-construir lo nuevo y un modo de hacer propio lo ajeno" (Fernández, 2000, pp. 96; 108).

La modalidad opera como una matriz que está en permanente reconstrucción y sobre la cual se van incluyendo los nuevos aprendizajes que van transformándola; de todos modos, la matriz sigue quedando estructural, si bien en su construcción participa el modo como los enseñantes hayan conseguido reconocer y querer al sujeto como sujeto aprendiente y como sujeto enseñante, y la significación que en el grupo familiar de origen se le haya dado a conocer (Reaño, 2011).

Señala Fernández (2000) la importancia subjetivante del aprendizaje, porque al aprender el sujeto construye y transforma los conocimientos que incorpora, a la vez que transforma la situación en que está aprendiendo y al propio enseñante. Así identifica cuatro modalidades de aprendizaje y enseñanza que constituyen dicho empobrecimiento: 1. Hipo-asimilación, en la cual los esquemas de objetos permanecen empobrecidos, así también la capacidad de coordinarlos. Por lo tanto, se puede observar un déficit lúdico y una disfunción del rol anticipatorio de la imaginación creadora. 2. Hiper-asimilación, donde prevalece la internalización prematura de los esquemas, con un predominio lúdico que desrealiza negativamente el pensamiento. 3. Hipo-acomodación que aparece cuando no se ha respetado el tiempo del sujeto ni su necesidad de repetir muchas veces la misma experiencia. Y, 4. Hiper-acomodación marcada por la sobre-estimulación de la imitación. El sujeto puede cumplir con las consignas actuales, pero no dispone con facilidad de sus expectativas ni de su experiencia previa. Estas modalidades, si se 'congelan' en una persona hacen que siempre y en cualquier situación la utilice de manera rígida, a diferencia de una persona con un tipo de modalidad de aprendizaje saludable (Ciancaglini, 2016).

En síntesis, la modalidad de aprendizaje supone un modo particular de organización entre una serie de elementos heterogéneos: (a) cierto modelo relacional entre sí mismo como quien conoce, el otro como quien puede conocer y el objeto de conocimiento como objeto que se construirá entre ambos; (b) un reconocimiento de sí mismo como autor; (c) un tipo de 'relación con el saber'; (d) la facilitación o restricción de vínculos solidarios con pares de la misma faja etaria; y (e) experiencias de vivencia de satisfacción en cuanto a ser sostén o tener algo para dar al otro ser bien recibido (Ventura, 2015).

Desde otro enfoque teórico complementario al de las modalidades de aprendizaje, basado en los estilos cognitivos, Ventura (2015) considera que se podría desarrollar una perspectiva estilística educativa como una versión alternativa al enfoque de las 'dificultades de aprendizaje' concebidas en un sentido restringido. Así, describe los estilos cognitivos como aquellos que: (1) definen un rasgo bipolar estable representado a lo largo de un continuo; (2) están relacionados con dimensiones cognitivas y no cognitivas de la persona; (3) intentan describir formas o modos de procesamiento de la información, estrategias a la hora de enfrentarse a la resolución de una tarea determinada, más que el resultado de la ejecución en esa tarea y, (4) son adquiridos en la primera infancia y son susceptibles de modificación.

En el término estilo de aprendizaje confluyen una variedad de diferencias que distinguen a una persona de otra. Existen cuatro funciones que todos los sujetos realizan cuando interactúan con una situación, persona, información o idea: primero, observa, a continuación, piensa sobre lo que ha observado, reacciona y, en último lugar, actúa. Estas funciones básicas de todo estilo de aprendizaje determinan cuatro relaciones: está relacionado con la cognición, la formación de conceptos, el afecto y los sentimientos y el comportamiento. Por lo tanto, cuatro serían las dimensiones de los estilos de aprendizaje: 1. Estilos de aprendizaje relacionados con las formas preferidas de los estudiantes de percibir la información (canales de aprendizaje): estilo visual, estilo verbal-auditivo. 2. Estilos de aprendizaje relacionados con las formas preferidas de los estudiantes de procesar la información: estilo global, estilo analítico. 3. Estilos de aprendizaje relacionados con las formas preferidas de los estudiantes de planificar su tiempo en el cumplimiento de sus metas como aprendices: estilo planificado y estilo espontáneo. 4. Estilos de aprendizaje 
relacionados con las formas preferidas de los estudiantes de orientarse hacia la comunicación y sus relaciones interpersonales en el aprendizaje: estilo cooperativo, estilo independiente o individual.

En suma, comprender que la estilística educativa supone que el profesorado pueda diseñar procesos de aprendizaje y procesos de enseñanza ajustables, orientados a incrementar el desempeño del estudiantado, es otra respuesta posible para que lo que ocurra en las aulas tenga algún sentido.

Por lo tanto, uno de los desafíos que enfrenta la escolarización obligatoria hoy es reconocer la diversidad inherente al ser humano y fomentar un nuevo modo de habitar las escuelas, concebir sus actores y diseñar los procesos de enseñanza y aprendizaje al interior de cada institución y cada aula.

\section{SÍNTESIS Y REFLEXIONES FINALES}

¿Qué hacer para que lo que ocurra en las aulas tenga algún sentido? ¿Qué hacer hoy con la escuela moderna?

Seria falaz pensar que hay respuestas distintas si se trata de situaciones de enseñanza presenciales o situaciones de enseñanza a distancia mediadas por tecnologías, porque no hay que confundir el aula (presencial o en entorno virtual) con la clase (situación de enseñanza). Lo central es la clase, es situada y, donde el aula y la escuela son sus contextos, entre otros contextos.

A lo largo del texto se han presentado algunas respuestas desde la perspectiva histórica, la psicología social, la pedagógica, la didáctica y la psicopedagógica. Asimismo, se ha sostenido que, estas respuestas tienen que darlas los gestores y administradores responsables de las políticas públicas en materia de educación y los responsables de cada uno de los centros escolares. También se señaló que los cientistas de la educación, teóricos e investigadores, deben aportar sus respuestas.

Asimismo, se sostuvo que también las familias y el estudiantado deben explicitar sus necesidades y demandas para que lo que se enseña y, se pretende que se aprenda, tenga sentido personal y relevancia social. Finalmente, se enfatizó en que corresponde que el profesorado dé respuestas. Estas reflexiones finales se focalizarán en el profesorado.

Para que lo que ocurra en las aulas y las escuelas tenga algún sentido, el profesorado tiene que considerar que las necesidades, inquietudes, intereses propios de cada sujeto, inciden fuertemente en el proceso de subjetivización del saber y del conocimiento. Por lo tanto, los procesos de subjetivación hoy tienen que ser problematizados y así promover nuevos vínculos del estudiantado con el conocimiento y nuevas formas de interacción en la escuela y el aula.

Para ello, resulta central conocer y aceptar otras formas de conocer, formas personales, formas propias de libidinización de los objetos de conocimiento: es necesario habilitar modalidades personales de aprender. Al mismo tiempo, el profesorado tiene que poder 'habilitarse' modalidades personales de enseñar.

Esto entra en tensión con los modelos de conocimiento, enseñanza y aprendizaje propios de la modernidad que implican posiciones subjetivas pasivas, receptivas, disciplinables y de carácter universal.

En su lugar, en este cambio de época, hay que reconocer que, "la subjetivización del conocimiento pone en juego la propia actividad del sujeto, sus intereses, sus particularidades y las capacidades individuales con que cuenta para acceder al saber, producirlo o apropiarse" (Da Porta, 2015, p. 3).

Por lo tanto, este cambio de época es una oportunidad para cambiar al sujeto pedagógico moderno y, para ello, se debe considerar que un mismo individuo puede ser sede de múltiples procesos de subjetivación, según los dispositivos con los que interactúe (Agamben, 2007). 
En ese sentido, el diseño de dispositivos distintos a los implementados por la matriz escolar moderna es posibles, como por ejemplo las aulas heterogéneas, ya aludidas en el Desarrollo del artículo. Para ello, se requiere de un profesorado propositivo, proactivo, con vocación. El diseño de otros dispositivos es una acción que surge de la pasión por el conocimiento y su difusión, requiere de la reflexión para llegar a propuestas de valor. En definitiva, el diseño de nuevos dispositivos y escenarios áulicos e institucionales, requiere de innovación; es decir, de esa energía propia del sujeto y las instituciones que busca generar y ser parte de procesos de cambio y transformación en orden al bien común.

Un profesorado propositivo, en líneas generales, es aquel capaz de desnaturalizar lo existente haciendo un ejercicio de extrañamiento; es decir, de distanciamiento comprometido con la realidad, con el fenómeno que analiza y quiere comprender para trasformar.

Un profesorado propositivo es aquel capaz de configurar y reconfigurar el aula como espacio del encuentro y la clase como situaciones de interacción entre subjetividades, valores, contenidos curriculares (conocimiento y saberes), proyectos compartidos y cooperativos, realizaciones colaborativas instituyendo otra gramática escolar. Es aquel capaz de promover procesos de de-construcción de RS en sí mismo y la institución escolar y de construcción de otras.

Un profesorado propositivo es el que no busca mejorar la escuela, el aula, las clases; sino que es quien pasa de la lógica de los proyectos de mejora educativa a la lógica de proyectos de innovación educativa.

Por lo tanto, ante el desfondamiento de las instituciones de la modernidad no se trata de ir 'más allá' de lo instituido, se trata, más bien, de instituir otra escuela, otro sujeto pedagógico, otras relaciones, otras interacciones, otras prácticas de enseñanza desde el interior de las aulas que irradie hacia afuera.

Como plantea Rivas (2017), la matriz escolar tradicional, pese a las profundas transformaciones de las últimas décadas, funciona todavía hoy en día si bien, en gran medida, las escuelas fueron perdiendo su base institucional compartida que las separaba de la sociedad. Por ello, la innovación educativa implica cambiar elementos de la matriz escolar tradicional para generar en el estudiantado capacidades de actuar y transformar su destino.

Entonces, no se trata de proponer cambiarlo todo porque, "las escuelas no solo cumplen hoy una función social decisiva; sino que tienen los secretos mejor guardados de la institucionalización del aprendizaje" (Rivas, 2017, p. 28).

Como ya se anticipó, innovar es dar cauce a esa fuerza vital, presente en escuelas, el profesorado que es capaz de reconocer las limitaciones de la matriz educativa tradicional y alterarla para el beneficio de los derechos a los aprendizajes de los sujetos: innovar es alterar los elementos de un orden escolar que apagan o limitan el deseo de aprender; no se trata de mejorar lo que hay. Innovar implica situar el ambiente del aula y la escuela en un nuevo espacio para favorecer los aprendizajes en profundidad en el estudiantado para alimentar su voluntad, su deseo de aprender, su compromiso social (Rivas, 2017).

En la convicción de que ninguna entidad, ni proceso humano es permanente y definitivo, sino que son construcciones sociales, políticas, históricas, culturales, se desarrollaron algunas categorías conceptuales que permiten pensar otros formatos escolares e innovar en el diseño de aulas heterogéneas y situadas; porque los dispositivos tienen que ser situados, no corresponde en este ensayo presentar ejemplos: ese diseño compromete la creatividad y la responsabilidad de cada persona docente.

En síntesis, este análisis permite concluir que, en definitiva, no se trata de 'romper' con la escuela existente, sino que desde lo existente es necesario y posible instituir un movimiento sinérgico cambio-continuidad, conservación-transformación poniendo en el centro la institucionalización de los aprendizajes y la tarea de enseñar. Por lo tanto, hay innovación o hay fracaso. 


\section{REFERENCIAS}

Abric, J-C. (1994). Practiques sociales et representatios. France: Presses univertiaires de France.

Agamben, G. (2007). "¿Qué es un dispositivo?". En Biblioweb Caosmosis. Disponible en: http://caosmosis.acracia.net $/ \mathrm{p}=700$.

Ahumada, P. (2005). La evaluación auténtica: un sistema para la obtención de evidencias de los aprendizajes. Perspectiva Educacional, Formación de Profesores, (45):11-24.

Anijovich, R. (2014). Gestionar una escuela con Aulas Heterogéneas. Buenos Aires: Paidós.

Anijovich, R. y Cappelletti, G. (2017). La evaluación como oportunidad. Buenos Aires: Editorial Paidós.

Bartolomé-Pina, A. (2020). Cambios educativos en tiempos de pandemia. Revista Innovaciones Educativas, (22), №. Especial:13-17.

Camilloni, A. et al., (2008). El saber didáctico. Buenos Aires: Paidós.

Carlini López, L. A. (2020). El duelo educativo y el rediseño como desafío de superación. Revista Innovaciones Educativas, (22), №. Especial:33-35.

Chevallard, Y. (1998). La transposición didáctica. Del saber sabio al saber enseñado. Buenos Aires: Aique.

Ciancaglini, M. (2016). Modalidad de aprendizaje y comunicación familiar. [Trabajo final Licenciatura en Psicopedagogía. Universidad FASTA Facultad de Ciencias de la Educación, Mar del Plata, Argentina].

Coll, C. (1995). Psicología y currículum. Buenos Aires: Aique.

Da Porta, E. (2015). Medios, tecnologías y redes. Recursos para el conocimiento y reconocimiento de sí. AVATARES de la comunicación y la cultura, (9):1-17.

Díaz Barriga, F. (2005). Enseñanza Situada. Un vínculo entre la escuela y la vida. México: Mc Graw Hill.

Díaz, A. G. (2020). Tiempos de pandemia y enseñanza universitaria: recrear las propuestas metodológicas entre el hogar y las plataformas de medios conectivos. Revista Innovaciones Educativas, (22), No. Especial:50-63.

Durkheim, E. [1911] (1984). Educación y Sociología. Buenos Aires: Colofón.

Duveen, G. y Lloyd, B. (2003) Las representaciones sociales como una perspectiva de la psicología social. En J. Castorina (compilador). Representaciones sociales. Problemas teóricos y conocimientos infantiles. Buenos Aires: Gedisa.

Edelstein, G. (2013). Formary formarse en la enseñanza. Paidós.

Fernández, A. (2000). Los idiomas del aprendiente Análisis de modalidades de enseñanza en familias, escuelas y medios. Buenos Aires: Nueva Visión.

Foucault, M. (1975). Las palabras y las cosas. Buenos Aires: Siglo Veintiuno.

Jodelet, D. (1986) La Representación Social: fenómenos, concepto y teoría. En S. Moscovici, Psicología Social. Buenos Aires: Paidós.

Lewkowicz, I. (2004) Escuela y ciudadanía. En C. Corea y Lewkowicz, I. Pedagogía del aburrido. Escuelas destituidas, familias perplejas. Ecuador: Paidós Educador.

Litwin, E. (2008). El oficio de enseñar. Condiciones y contextos. Editorial Paidós.

Mead, M. (1980). Cultura y Compromiso. Estudio sobre la ruptura generacional. Buenos Aires: Gedisa.

Moscovici, S. (1986). Psicología Social. Buenos Aires: Paidós. 
Pineau, P. (2005) ¿Por qué triunfó la escuela?, o la modernidad dijo: 'Esto es educación', y la escuela respondió: 'yo me ocupo'. En P. Pineau, et al. La escuela como máquina de educar. Tres escritos sobre un proyecto de la modernidad. Buenos Aires: Paidós Cuestiones de Educación.

Puiggros. A. (1990). Sujetos, Disciplina y Curriculum en los orígenes del sistema educativo argentino. Buenos Aires: Galerna.

Reaño, A. (2011). El desarrollo de matrices de aprendizajes en contextos familiares violentos. [Tesis de grado de la Licenciatura en Psicopedagogía. Facultad de Investigación y desarrollo educativo de la Universidad Abierta Interamericana].

Ricci, C. (2020). Cuatro tesis para una Psicopedagogía. Apuntes sobre el quehacer psicopedagógico; el objeto psicopedagógico; la Psicopedagogía y la Ciencias Psicopedagógicas y, la investigación psicopedagógica e investigación en Psicopedagogía. Revista Aprendizaje hoy, XL(101/102):75-116.

Rivas, A. (2017). Cambio e innovación educativa: las cuestiones cruciales. Documento básico. XII Foro Latinoamericano de Educación. Buenos Aires: Santillana.

Salinas Ibáñez, J. (2020). Educación en tiempos de pandemia: tecnologías digitales en la mejora de los procesos educativos. Revista Innovaciones Educativas, (22), No. Especial:17-21.

Sangrà Morer, A. (2020). Tiempo de trasformación educativa. Revista Innovaciones Educativas, (22), №. Especial:22-27.

Stenhouse, L. (1999). Enseñanza y filosofías de la enseñanza. En S. Gvirtz y M. Palamidessi, (2004). El ABC de la tarea docente: currículum y enseñanza. Aique.

OMS (2020). COVID-19: cronología de la actuación de la OMS. Recuperdo de https://www.who.int/es/ news/item/27-04-2020-who-timeline---covid-19

Ventura, A. (2015). Dificultades de aprendizaje y psicopedagogía: una perspectiva estilística. Revista Construção psicopedagógica, 23(24):6-19. 